EGU2020-494

https://doi.org/10.5194/egusphere-egu2020-494

EGU General Assembly 2020

(c) Author(s) 2020. This work is distributed under

the Creative Commons Attribution 4.0 License.

\title{
Are human activities main drivers of soil organic carbon losses in mountain rainfed agroecosystems?
}

\author{
Ivan Lizaga ${ }^{1}$, Leticia Gaspar ${ }^{1}$, Laura Quijano ${ }^{2}$, Maria Concepción Ramos ${ }^{3}$, and Ana Navas ${ }^{1}$ \\ ${ }^{1}$ EEAD-CSIC, Soil and Water, Zaragoza, Spain (ilizaga@eead.csic.es) \\ ${ }^{2}$ Université Catholique de Louvain, Georges Lemaître Centre for Earth and Climate Research - Earth and Life Institute, \\ Belgium \\ ${ }^{3}$ University of Lleida, Environment and Soil Sciences, Lleida, Spain
}

One of the principal soil degradation problems affecting European agroecosystems is the loss of topsoil by water erosion. In dry climates, soil erosion is led by two main factors, human activities such as agriculture and extreme episodic rainfalls. However, agriculture plays a crucial role in leaving the soils unprotected during part of the year. Thus, extreme rainfall can easily remove the topsoil with the subsequent removal of nutrients in surface soil layers and the reduction of soil quality.

To assess the effects of extreme storms in rainfed agriculture catchments on soil organic carbon removal, surface soil samples from different land uses were collected in a medium-sized catchment at the foot of Santo Domingo range. The study area was mostly cultivated at the beginning of the 19th century but changed to rangeland and afforestation forest in the last 50 years. The remaining cropland area is mostly rainfed agriculture that leaves soils unprotected in periods when erosive storms occur (autumn convective rainfalls). The main land uses are croplands, pine afforestation, scrubland and Mediterranean forest. To track the export of soil organic carbon associated to mobilised sediment occurring under storm events, channel bed sediment samples were collected along the principal streams of the drainage network during regular flow, after a regular storm event, and after an extreme storm event. The contents of soil organic carbon (SOC), SOC fractions and grain size were analysed and compared for the three sampling campaigns. The results show a gradual decrease of the fine fraction from regular flood samples to samples collected after the extreme event. However, the SOC showed a sharp decrease in the post-extreme event samples, with higher decreases in the active carbon fraction (ACF) than in the stable carbon fraction (SCF).

Our findings highlight the substantial in situ hazards of extreme rainfall events removing soil organic carbon from topsoils and exporting fine sediment and nutrients out of the catchment with important indirect impacts on water resources both quantity and quality. 